\title{
Numerical Simulation of Dual Laterolog Response in Directional Wells and Development of Correction Plate
}

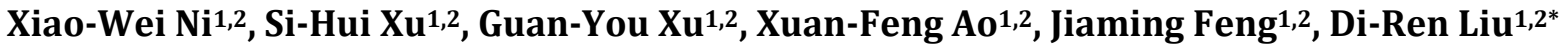 \\ ${ }^{1}$ Key laboratory of Exploration Technologies for Oil and Gas Resources, Ministry of Education, Yangtze University, Wuhan, \\ China \\ ${ }^{2}$ College of Geophysics and Oil Resources, Yangtze University, Wuhan, China \\ Email:737190269@qq.com, *liudr666@163.com
}

How to cite this paper: Ni, X.-W., $\mathrm{Xu}$, S.-H., Xu, G.-Y., Ao, X.-F., Feng, J.M. and Liu, D.-R. (2017) Numerical Simulation of Dual Laterolog Response in Directional Wells and Development of Correction Plate. Open Journal of Yangtze Gas and Oil, 2, 237-248.

https://doi.org/10.4236/ojogas.2017.24019

Received: June 21, 2017

Accepted: October 27, 2017

Published: October 30, 2017

Copyright $\odot 2017$ by authors and Scientific Research Publishing Inc. This work is licensed under the Creative Commons Attribution International License (CC BY 4.0).

http://creativecommons.org/licenses/by/4.0/

\begin{abstract}
Since the dual laterolog response is affected by various environmental factors, the instrument response is difficult to reflect the true resistivity of the formation. Plate correction is a common method of resistivity logging environmental correction. Three-dimensional layered media model was established, and the dual laterolog response in directional wells was simulated by three-dimensional finite element method. The influence of environmental factors such as wellbore, well deviation, surrounding rock and mud intrusion on the response of dual laterolog is analyzed emphatically. Therefore, the environmental factors correction plate with different well deviations is constructed, and the plates can be used to guide the dual laterolog environment correction work for better reservoir identification and oil and gas evaluation.
\end{abstract}

\section{Keywords}

Dual Laterolog, Three-Dimensional Finite Element, Environmental Factors, Correction Plates

\section{Introduction}

Dual laterolog is one of the important logging methods to obtain formation resistivity information, widely used in oil and gas field exploration and development [1] [2]. The resistivity obtained by the dual laterolog is frequently affected by various environmental factors [3] [4]. The correction of the resistivity measured by the instrument is the basis for accurately obtaining the formation resistivity information. The current environmental factor correction plates are often 
calculated based on two-dimensional axisymmetric formation [5] [6]. Xie Guanbao [7] simulated the response of dual laterolog tool in two-dimensional axisymmetric model, and provided the basis for dual laterolog inversion in straight well condition; on the basis of optimizing the traditional double electrode system, Tong Maosong [8] developed a corresponding environmental factor correction chart. However, in the actual production practice, horizontal wells and various inclinations wells are universal [9] [10], and the correction plates produced in two dimensions are not valid for horizontal wells and various inclinations wells to make a better explanation [11] [12]. At present, there are few studies on forward modeling of dual laterolog in directional wells, so the research of the response of the instruments in the case of inclined wells/horizontal wells is needed. In this paper, three-dimensional finite element numerical simulation technique is used to analyze the response characteristics of dual laterolog logging. The calibration plate of environmental factors such as wellbore, surrounding rock/layer thickness, well deviation and mud intrusion are developed. The correction plate can realize the rapid correction of the influence of the environmental factors of the dual laterolog logging. After the plate interpolation correction, the dual laterolog logging resistivity curve reflects the reservoir real resistivity information, which is of great significance to qualitatively judge the oil and gas reservoir and quantitatively calculate the oil saturation.

\section{Finite Element Numerical Simulation}

In this paper, the response of dual laterolog is simulated by finite element method. The finite element method (FEM) is a widely used numerical simulation method, and its basic steps are shown in Figure 1.

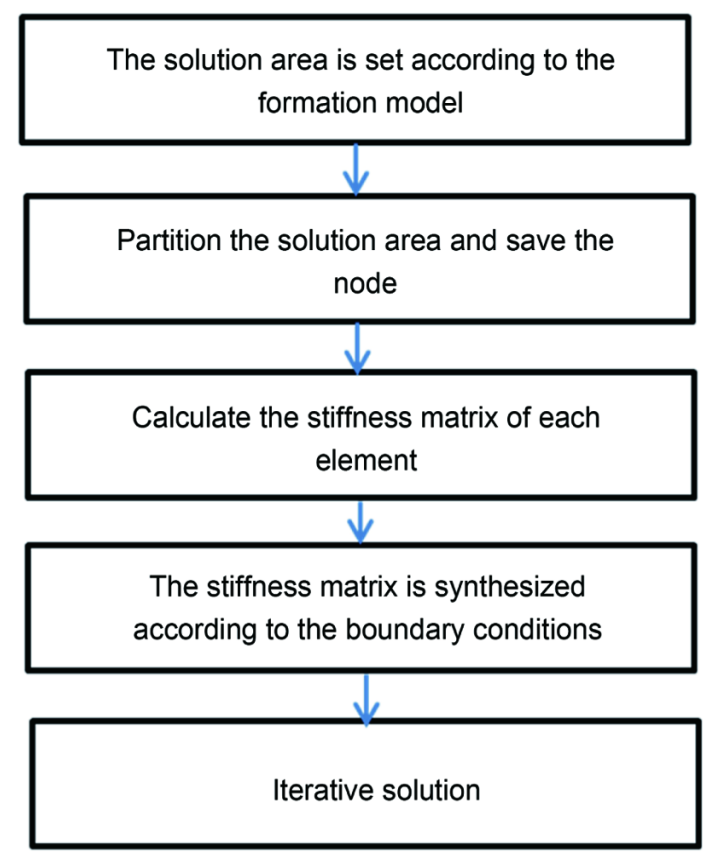

Figure 1. Flow chart of finite element method. 
To determine the response of the dual laterolog is to ask for a continuous and smooth potential function [13] [14], under certain conditions to meet Formula 1.

$$
\nabla \cdot\left(\frac{1}{R} \nabla \mu\right)=0
$$

In the Formula (1), $R$ is the regional dielectric resistivity, $\Omega \cdot \mathrm{m}$; and $\mu$ is the potential function, $\mathrm{V}$.

The three-dimensional finite element method can be used to calculate the response of the dual laterolog, and the problem can be reduced to the extreme value problem of the general function $\phi$ [15] [16].

$$
\phi=\frac{1}{2} \iiint_{\Omega}\left(\left(\frac{\partial \mu}{\partial x}\right)^{2}+\left(\frac{\partial \mu}{\partial y}\right)^{2}+\left(\frac{\partial \mu}{\partial z}\right)^{2}\right) \mathrm{d} x \mathrm{~d} y \mathrm{~d} z-\sum_{E} I_{E} \mu_{E}
$$

In the Formula (2), $I_{E}$ is the current sent by the electrode, $\mu_{E}$ is the potential on the electrode, the integral interval is the space surrounded by the instrument surface and the infinite boundary, $E$ is the number of electrodes, and the sum is for all the electrodes.

The boundary conditions based on:

1) The first type of boundary conditions: $\mu$ is known constant in the constant voltage electrode; $\mu$ is unknown constant in the constant current electrode.

2) The second type of boundary conditions: the constant current electrode surface to meet:

$$
\int_{\sigma_{m}} \frac{\partial u}{\partial x} \cdot \boldsymbol{n d} \tau=I
$$

In the Formula (3), $\tau$ represents the surface of the entire electrode, the vertical electrode is normal, and $I$ represents the current emitted by the electrode, $\sigma_{m}$ indicates the slurry conductivity.

3) On the insulated boundary:

$$
\frac{\partial \mu}{\partial n}=0
$$

In the actual simulation process, the electric field of the two detection modes of the dual laterolog can be formed by three sub-field superposition [17] [18]. So the total electric field is synthesized by assigning different weighting coefficients to each subfield and then superimposing the electric field.

The three subfields are only $A_{0}$ emission potentials, only $A_{1}, A_{1}^{\prime}$ transmit unit current, only $A_{2}, A_{2}^{\prime}$ emit unit current, the formation of the electric field.

$$
\mu_{\mathrm{z}}=\mu_{0}+C_{1} \mu_{1}+C_{2} \mu_{2}
$$

Among them, $\mu_{z}$ is the total electric field in each detection mode, $\mathrm{V} ; \mu_{0}$, $\mu_{1}, \mu_{2}$ is the corresponding electric field, $\mathrm{V} ; C_{1}, C_{2}$ is the weighting coefficient of each sub-field. Taking the shallow lateral logging response as an example, the potential and current conditions according to the shallow lateral logging mode are: 


$$
\begin{gathered}
\mu_{M_{1}}=\mu_{M_{2}} \\
1+I_{1}+I_{2}=0
\end{gathered}
$$

In the Formula (6), $\mu_{M_{1}}, \mu_{M_{2}}$ are the potentials on the supervisory electrodes $M_{1}, M_{2}, \mathrm{~V} ; I_{1}$ and $I_{2}$ are the currents flowing out of the electrodes $A_{1}\left(A^{\prime}\right)$ and $A_{2}\left(A^{\prime}\right)$ respectively.

$$
\begin{gathered}
\mu_{0}\left(M_{1}\right)+C_{1} \mu_{1}\left(M_{1}\right)+C_{2} \mu_{2}\left(M_{1}\right)=\mu_{0}\left(M_{2}\right)+C_{1} \mu_{1}\left(M_{2}\right)+C_{2} \mu_{2}\left(M_{2}\right) \\
1+C_{1}+C_{2}=0
\end{gathered}
$$

According to (8)-(9), $C_{1}$ and $C_{2}$ can be obtained and then the shallow lateral logging response value can be acquired corresponding to the total electric field distribution.

$$
R_{\mathrm{S}}=K_{\mathrm{S}} \cdot \frac{\mu_{\mathrm{S}}\left(M_{1}\right)}{I_{0}}
$$

The apparent resistivity values in the shallow lateral logging mode can be obtained using the Equation (10).

\section{Formation Model}

Figure 2 and Figure 3 are the inclined well model and the horizontal well model respectively. In the directional well, the well axis intersects the stratigraphic normal direction, and the main factors of the dual laterolog response are borehole, well angle, surrounding rock/thickness, etc. The resistivity parameters of each part are different. The three-dimensional coordinate system is defined, the instrument center is the origin, the $Z$ direction is the shaft method, $Y$ is the direction of the vertical paper, and the $X$ direction is the vertical $Y, Z$ plane direction.

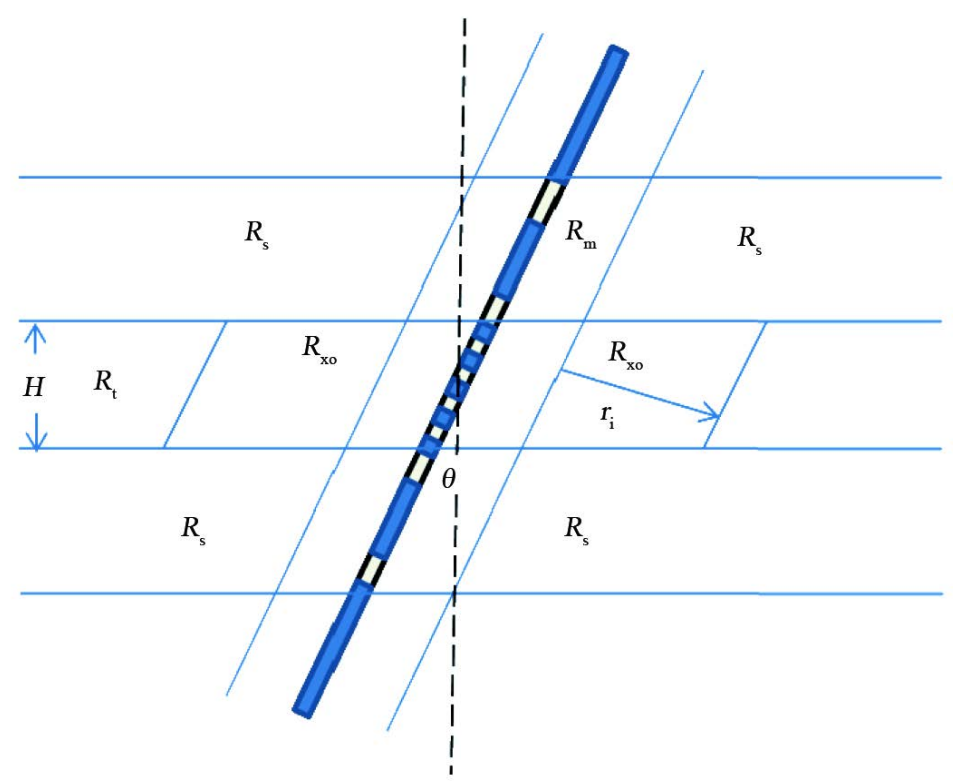

Figure 2. Inclined well model. 


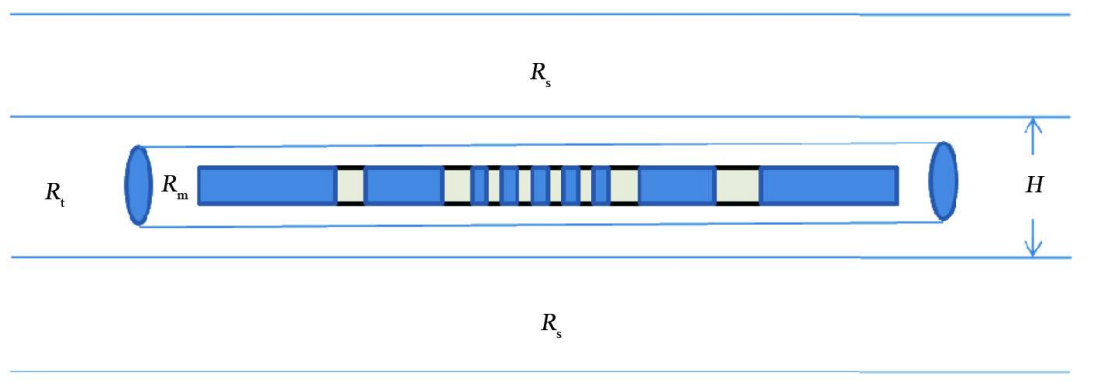

Figure 3. Horizontal well model.

\section{Correction Plate Development}

\subsection{Wellbore Correction}

The forward model uses the model shown in Figure 2. The target layer is large enough, the wellbore is located in the center of the target layer, the instrument is centered in the wellbore, and resistivity of target layer is expressed by $R_{\mathrm{t}}$ and the mud resistivity $\left(R_{\mathrm{m}}\right)$ is $1 \Omega \cdot \mathrm{m}$. The abscissa of the wellbore correction plate is the ratio of the resistivity of the target layer to the mud resistivity. The vertical axis of the well correction plate is the borehole correction coefficient Rllc/Ra, and the caliper size is the modulus. The caliper size is incremented from 6 in to 22 in, with an increase of 2 in each time. Figure 4 is a deep lateral logging wellbore correction plate, while Figure 5 is a shallow lateral logging wellbore correction plate.

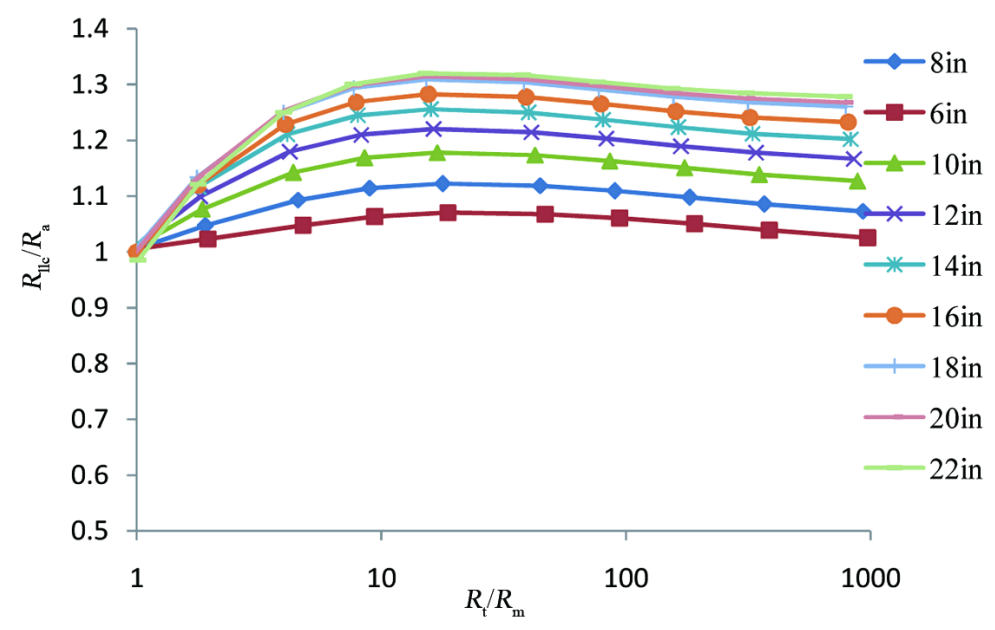

Figure 4. Deep lateral logging wellbore correction plate.

For the deep lateral logging, it can be shown from Figure 4 that when the ratio of the target layer resistivity to the mud resistivity $\left(R_{\mathrm{t}} / R_{\mathrm{m}}\right)$ is less than 20 , the wellbore correction coefficient of the deep lateral $\log$ is greater than 1 , gradually increasing with the $R_{\mathrm{t}} / R_{\mathrm{m}}$ increasing. When the ratio of the target layer resistivity to the mud resistivity $\left(R_{\mathrm{t}} / R_{\mathrm{m}}\right)$ is greater than 20 , the wellbore correction coefficient of the deep lateral logging is greater than 1 , but it decreases with the increase of $R_{\mathrm{t}} / R_{\mathrm{m}}$. It can be shown from Figure 5 that the correction coefficient of 
the shallow lateral logging has the following variation with the change of $R_{\mathrm{t}} / R_{\mathrm{m}}$; when the well diameter is less than $12 \mathrm{in}$, the correction coefficient decreases with the increase of $R_{\mathrm{t}} / R_{\mathrm{m}}$ and the correction coefficient is less than 1 . When the well diameter is more than $12 \mathrm{in}$, the correction coefficient increases with the increase of $R_{\mathrm{t}} / R_{\mathrm{m}}$, indicating the wellbore shunt effect obvious and the shallow lateral logging greatly influenced by the borehole.

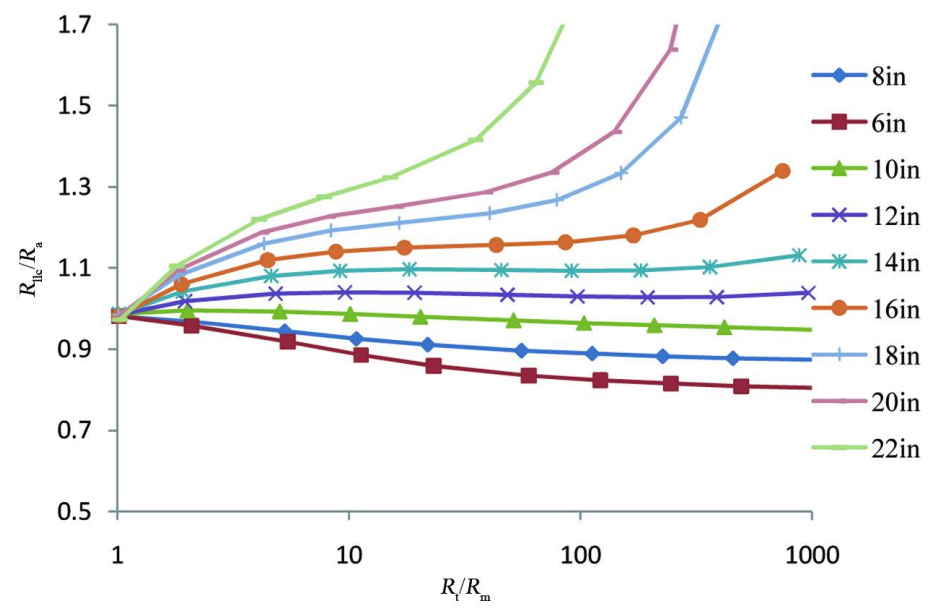

Figure 5. Shallow lateral logging wellbore correction plate.

\subsection{Well Deviation Correction}

The stratum is modeled with a three-dimensional stratigraphic model with a focal point of -0.5 and 0.5 , the thickness of target layer $(H)$ is $1 \mathrm{~m}$, the resistivity of target layer $\left(R_{\mathrm{a}}\right)$ is $20 \mathrm{ohms}$, the thickness of an upper and lower surrounding rock is infinite and resistivity is $5 \mathrm{ohms}$, the instrument is centered, and the mud resistivity $\left(R_{\mathrm{m}}\right)$ is $1 \mathrm{ohm}$. The results of the calculation are shown in Figure 6 and Figure 7, where the abscissa is the measurement of the abscissa deep; the ordinate is the apparent resistivity size.

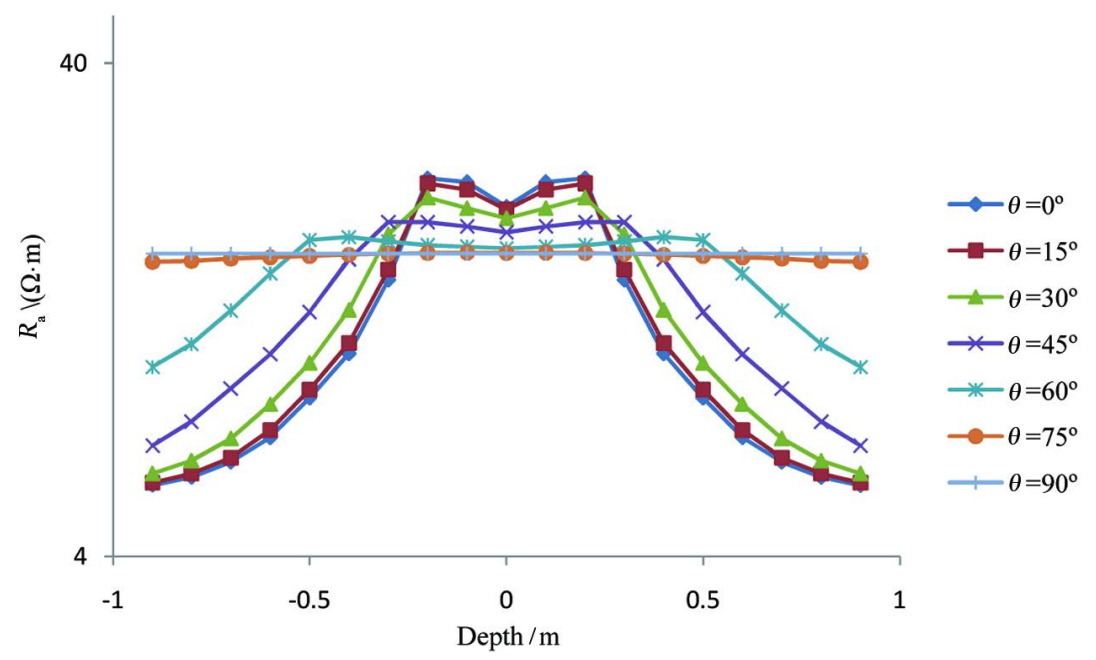

Figure 6. Shallow lateral logging response under different well bevels. 


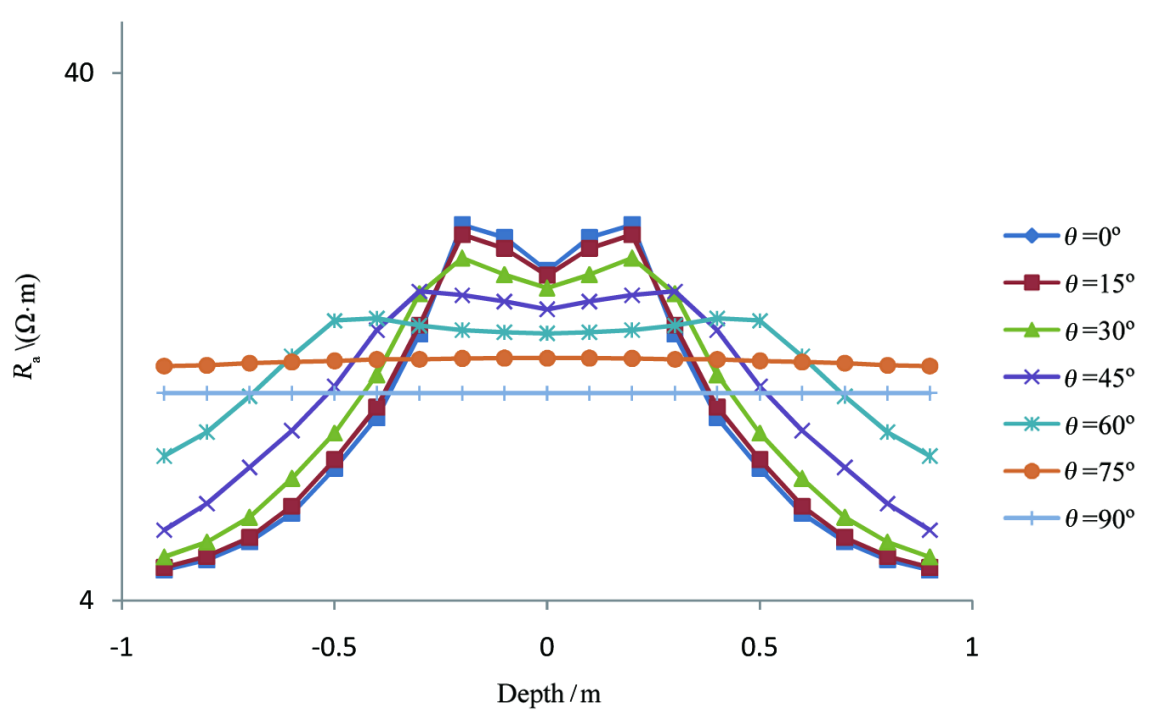

Figure 7. Deep lateral logging response under different well bevels.

It can be shown from Figure 6 and Figure 7 that the dual laterolog response is smaller with the increase of the inclination angle, because the current will flow vertically into the surrounding strata by the shield electrode in the dual laterolog. As the wellbore and the stratigraphic interface shows a certain angle, the current will flow into the surrounding rock, resulting in measurement results appear bias, which is mainly caused by low resistance of surrounding rock. When the well angle is less than $15^{\circ}$ for the dual laterolog, the instrument response is basically not affected by the angle of the well angle; and the degree of separation between the apparent resistivity curve increases with the increase of the well angle. At the same time, the instrument responds to the "distortion" near the interface of the layer is disappear, indicating that the instrument's layered ability is weakened and the instrument can not accurately identify the layer interface. The effect of the well angle on the deep lateral logging is greater than on the shallow lateral logging.

\subsection{Thickness Correction}

For the correction of the thickness and the surrounding rock, it is necessary to make a map of the surrounding rock/layer thickness with different inclination. The model of inclined well is established, and the influence of mud intrusion is not taken into account. A three-dimensional finite element numerical simulation method was used to calculate the multi sets of different types of surrounding rock and layer thickness forward model. Figures 8-11 are surrounding rock/layer thickness correction plates when the inclination angle is $0^{\circ}, 30^{\circ}, 60^{\circ}$ and $90^{\circ}$ respectively. The deep laterolog correction coefficient $\left(R_{\text {lld }} / R_{\mathrm{t}}\right)$ and the shallow laterolog correction coefficient $\left(R_{\mathrm{lls}} / R_{\mathrm{t}}\right)$ are the ordinate, the formation thickness is the abscissa, and the ratio of the true resistivity and the resistivity of the surrounding rock is modulo. 

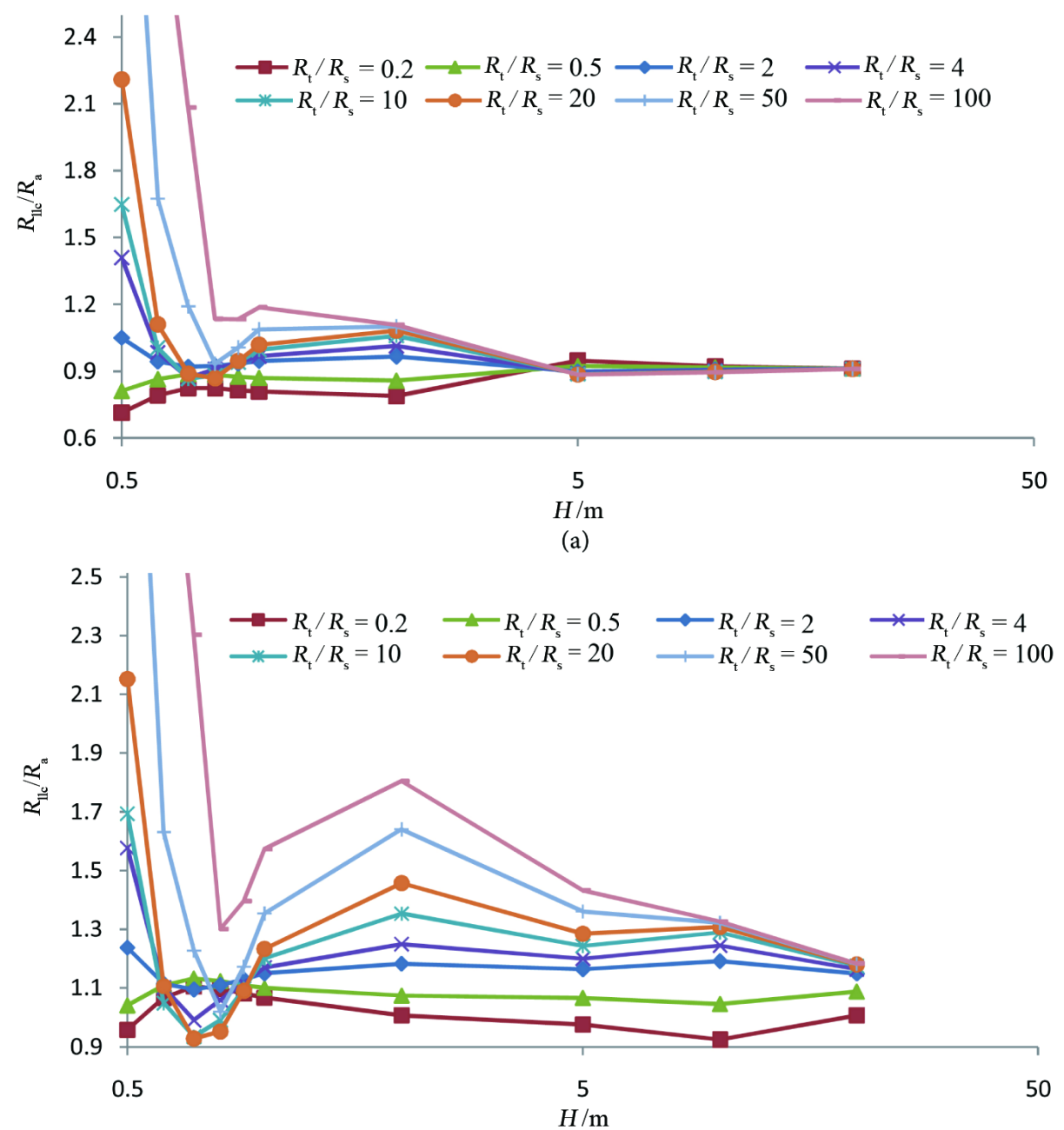

(b)

Figure 8. $\theta=0$, surrounding rock/thickness correction plate. (a) The shallow lateral; (b) The deep lateral.

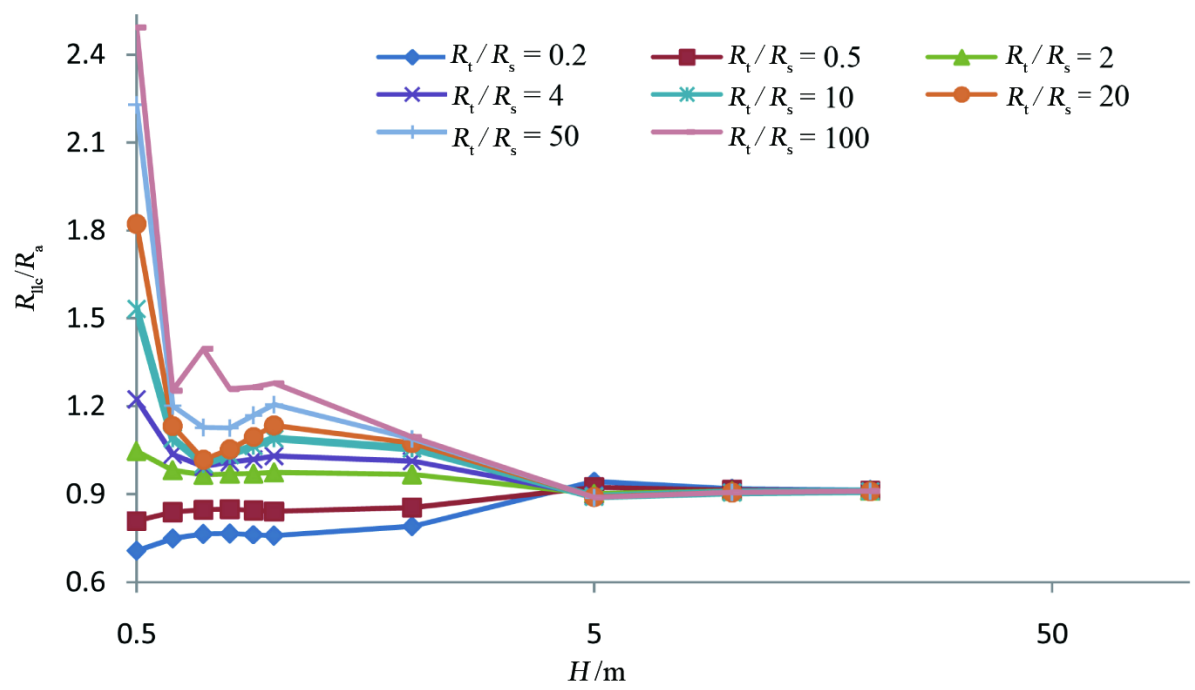

(a) 


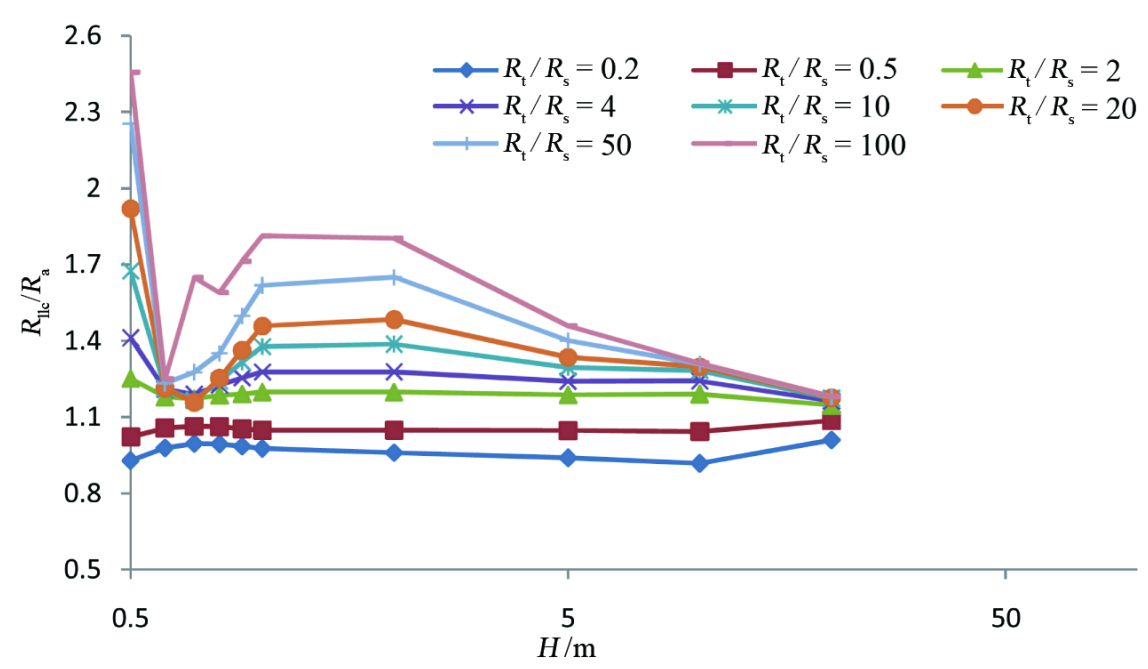

(b)

Figure 9. $\theta=30$, surrounding rock/thickness correction plate. (a) The shallow lateral; (b) The deep lateral.

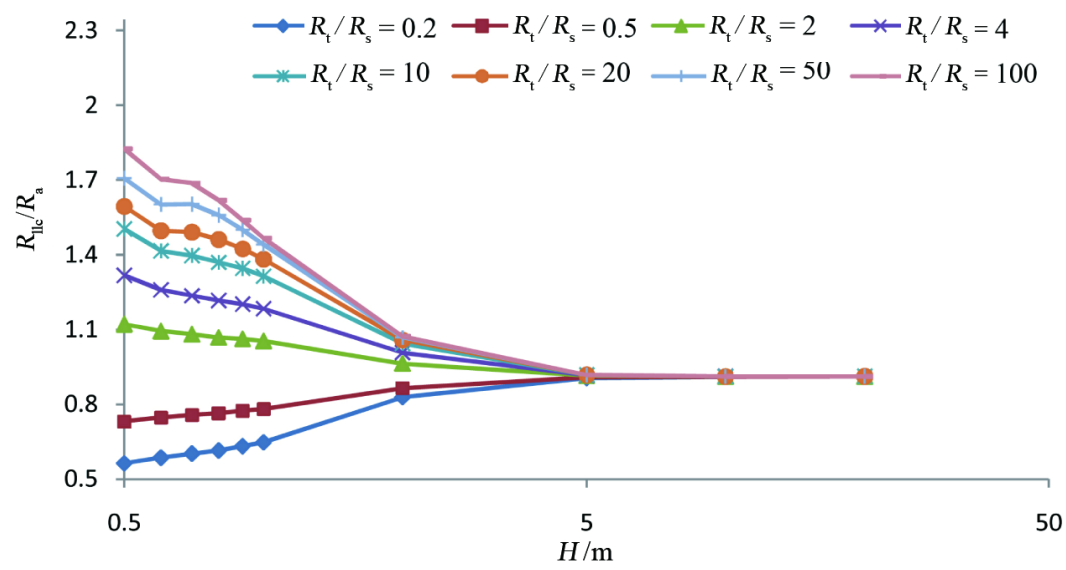

(a)

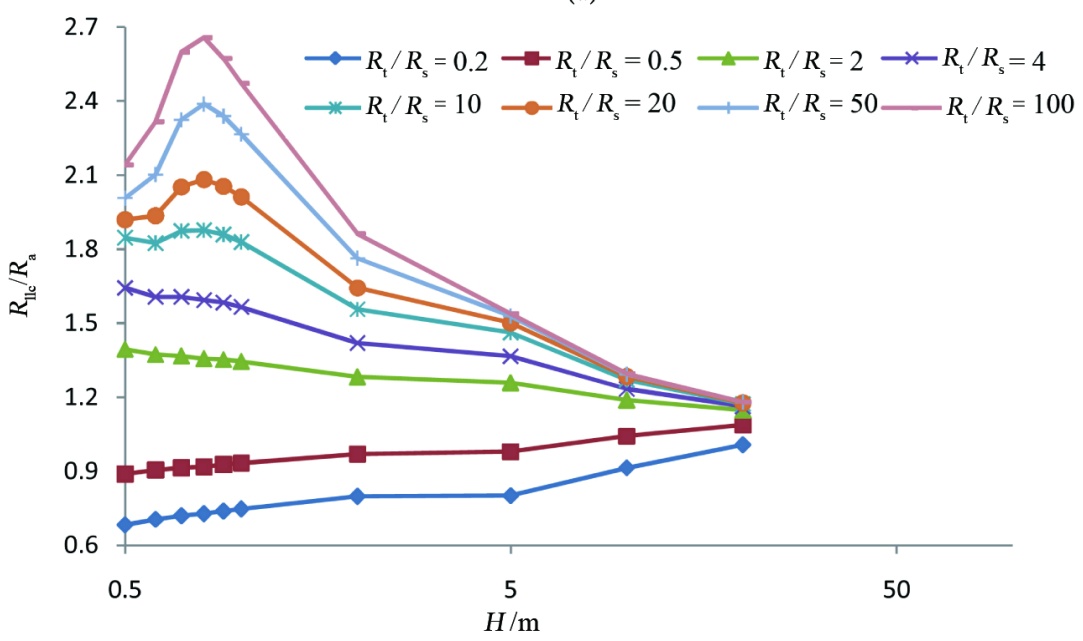

(b)

Figure 10, $\theta=60$, surrounding rock/thickness correction plate. (a) The shallow lateral; (b) The deep lateral. 


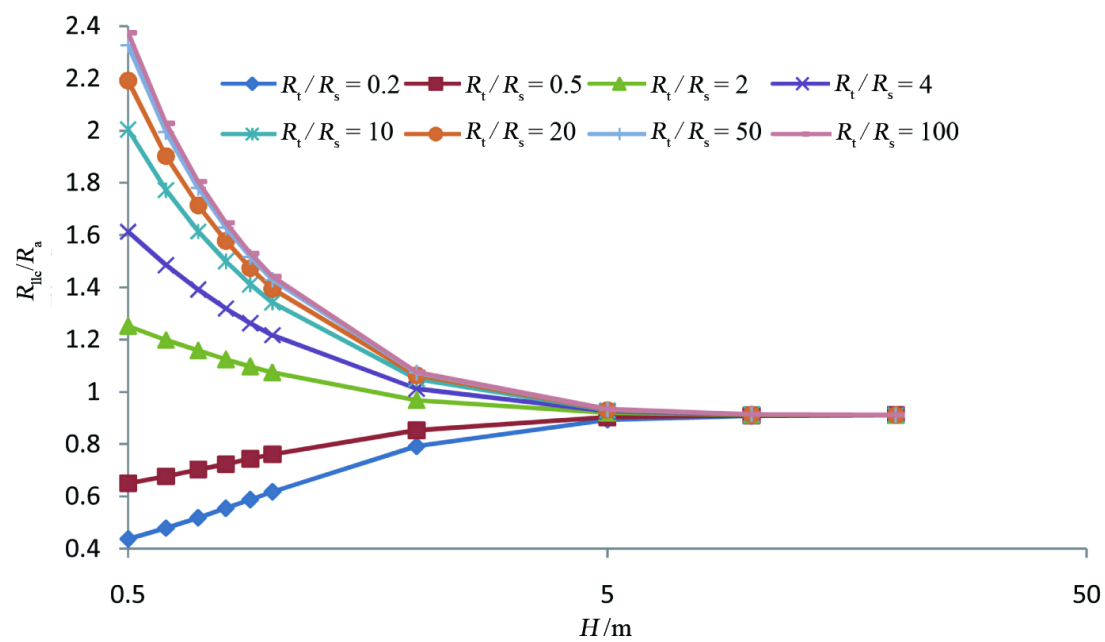

(a)

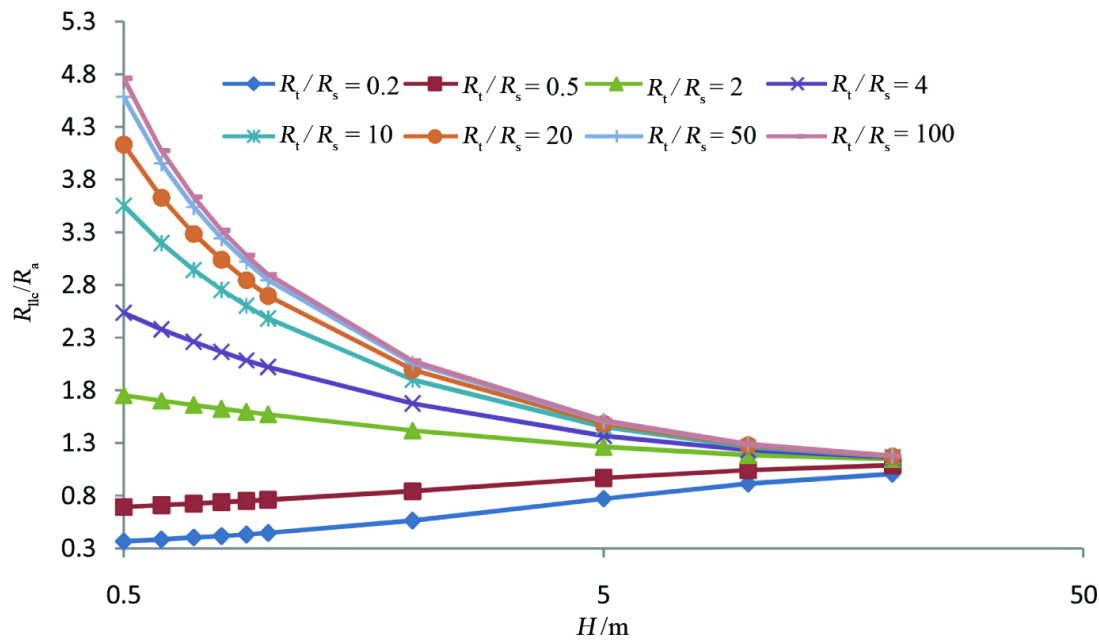

(b)

Figure 11. $\theta=90$, surrounding rock/thickness correction plate. (a) The shallow lateral; (b) The deep lateral.

It can be shown from Figures 8-11 that the difference of the surrounding rock/layer thickness correction plate at different inclination angles is large. The deep laterolog resistivity correction coefficient varies with the increase of the thickness of the target layer $(H)$, and its variation depends on the ratio of the resistivity of the surrounding rock to the resistivity of the target layer. When the resistivity of the surrounding rock is greater than the target layer resistivity, the correction coefficient is greater than 1 , indicating that the corrected resistivity is greater than the original apparent resistivity; When the resistivity of the surrounding rock is less than the resistivity of the target layer, the correction coefficient is less than 1 , indicating that corrected resistivity is lower than the original apparent resistivity. With the thickness of the target layer increasing, the deep laterolog correction coefficient curve gradually reduced, when the thickness of the layer up to $20 \mathrm{~m}$, the correction coefficient is close to 1 . Layer thickness correction is not necessary at this time. When the well angle is small, such as less than $30^{\circ}$, the correction coefficient does not change much, and the correction 
coefficient of different layer thickness is not large; with the increase of the inclination of the well, the correction coefficient gradually increases. When the angle is $60^{\circ}$, the correction factor changes greatly. This shows that the greater the deviation, the bigger influence on resistivity, the larger corresponding correction coefficient. In short, the greater the inclination and layer thickness, the greater the correction coefficient.

\subsection{Intrusion Correction}

The data obtained from the forward modeling numerical simulation is carried out with wellbore, well deviation, surrounding rock/thickness correction, which can be considered without the influence of borehole, well deviation, surrounding rock and eccentricity. Figure 12 is the mud intrusion correction plate.

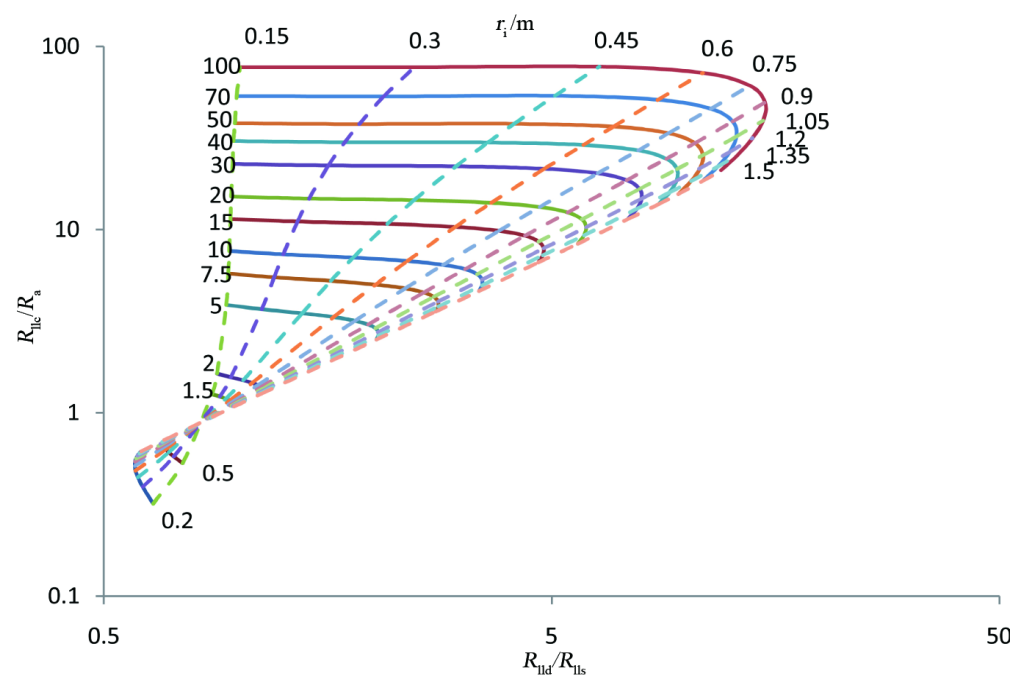

Figure 12. Mud intrusion correction plate.

\section{Conclusions}

In this paper, the response of dual laterolog is studied by finite element numerical simulation technique. The influence of borehole, well deviation, surrounding rock and mud intrusion on logging results is studied by finite element method. The following conclusions can be drawn from the calculation and analysis.

1) The borehole size has a large effect on the dual laterolog, in which the shallow lateral logging response is particularly affected by the borehole size.

2) When the inclination angle is less than $15^{\circ}$, the deviation of the well deviation has little effect on the dual laterolog. When the angle of the well is greater than $30^{\circ}$, the deviation of the well deviation has a great influence on the dual laterolog. With the increase of the inclination angle, the stratification ability of the dual laterolog will be weakened, and the stratified interface cannot be effectively identified.

3) The greater the difference between the resistivity of surrounding rock and the resistivity of the target layer, the greater the effect on the apparent resistivity. When the depth of mud invasion is less than $0.75 \mathrm{~m}$, the dual laterolog is sensi- 
tive to the change of mud invasion depth.

\section{References}

[1] Li, Z.J., Chen, Z.Q. and Zhang, K. (2016) Numerical Analysis of High Resolution Double Lateral Logging. Advances in Geophysics, No. 4, 1614-1619.

[2] D, S.G., Li, Z.Q. and Li, Z.Q. (2009) Then the Rapid Correction of the Effect of Horizontal Logging and the Influence of Thickness and Surrounding Rock. Petroleum Exploration and Development, 36, 725-729.

[3] Deng, S.G., Li, Z.Q., Fan, Y.R., et al. (2010) Simulation of Mud Invasion in Inclined Shaft and Numerical Simulation of Array Lateral Well Logging Response. Journal of Geophysics, 53, 994-1000.

[4] Li, C.X., Li, C.L., Zhou, C.C., et al. (2007) Influence of Fresh Water Drilling Fluid Invasion on Dual Induction and Dual Laterolog Response. Petroleum Exploration and Development, 34, 603-608.

[5] Tan, M.J., Gao, J., Zou, Y.L., et al. (2012) Study on Correction Method of Dual Laterolog Environment for Directional Wells under Saltwater Mud. Chinese Journal of Geophysics, 55, 1422-1432.

[6] Zhu, D.W. and Deng, S.G. (2009) Instrument Eccentricity Correction for Double Laterolog in Large Inclined Well. Petroleum Pipe and Instrument, 23, 58-61.

[7] Xie, G.B. (2014) Analysis of Dual Laterolog Response Characteristics and Environment Correction Method. Science and Technology Herald, 32, 74-78.

[8] Tong, M.S. and Song, J.H. (2014) Numerical Simulation of Dual Laterolog in $0.2 \mathrm{~m}$ Resolution. Advances in Geophysics, No. 5, 2251-2257.

[9] Tan, Y.J. and Yu, Y. (1997) Numerical Simulation of Dual Laterolog for Horizontal and High Angle Wells. Journal of Fudan University, Natural Science Edition, No. 6, 633-638.

[10] Xiao, J.Q., Zhang, G.J. (1995) Calculation. Journal of Geophysical Response of Induction Logging Level and Highly-Deviated Wells, No. 3, 396-404.

[11] Liu, D., Xia, P., Wan, G., et al. (2012) Dual Laterolog Response Characteristics of Fractured Carbonate Reservoirs in Horizontal Wells. Lithologic Reservoirs, 24, 1-4.

[12] Wan, W., Liu, D., Xia, P., et al. (2012) Influence of Eccentricity and Mud Invasion on Laterolog in Horizontal and Vertical Wells. Journal of the Petroleum and Natural Gas Journal, 34, 72-74.

[13] Zhang, G. (1980) Successive Approximation Method of Non-Homogeneous Dielectric Electric Field and Geometric Factor of Direct Current Logging. Journal of Geophysics, 23, 183-196.

[14] Zhang, G. (1984) Electrical Logging. Petroleum Industry Press, Beijing.

[15] Deng, S., Lu, C., et al. (2012) fracture Cave Stratum Bilateral Fracture Cave to the Logging Response of Petroleum Exploration and Development. Numerical Simulation, 39, 706-712.

[16] Deng, S., Tong, Z. and Fan, Y. (2006) Jen Tilted Anisotropic Formation. Numerical Simulation of Dual Laterolog Response. Acta Petrolei Sinica, 27, 61-64.

[17] Yao, D. (2010) Iterative Regularized Inversion of Dual Laterolog Data and Numerical Simulation of Multicomponent Induction Logging in Anisotropic Formation. Jilin University, Changchun.

[18] Chen, L. (2008) Three Dimensional Finite Element Numerical Analysis of Dual Laterolog Response in Inclined Wells and Horizontal Wells. Zhejiang University, Hangzhou. 